\title{
Sublethal neonicotinoid insecticide exposure reduces solitary bee reproductive success
}

\author{
Christoph Sandrock*, Lorenzo G. Tanadini ${ }^{\dagger}$, Jeffery S. Pettis ${ }^{\ddagger}$, Jacobus C. Biesmeijer ${ }^{\S}$, Simon G. Potts ${ }^{\rrbracket}$ and Peter \\ Neumann** \\ ${ }^{*}$ Swiss Bee Research Centre, Agroscope Liebefeld-Posieux ALP, Schwarzenburgstrasse 161, 3003 Bern, Switzerland, ${ }^{\dagger}$ SCI Research, SCI Center, \\ Balgrist University Hospital, University of Zurich, Forchstrasse 340, 8008 Zurich, Switzerland, ${ }^{*}$ United States Department of Agriculture-ARS Bee \\ Research Laboratory, Beltsville, MD 20705, U.S.A., ${ }^{\S}$ Netherlands Centre for Biodiversity Naturalis, PO Box 9517, 2300 RA, Leiden, The \\ Netherlands, "ISchool of Agriculture, Policy and Development, University of Reading, Reading RG6 6AR, U.K., and ${ }^{* *}$ Institute of Bee Health, \\ Vetsuisse Faculty and Faculty of Medicine, University of Bern, Länggass-Strasse 109a, 3001 Bern, Switzerland
}

\begin{abstract}
Pollinating insects provide crucial and economically important ecosystem services to crops and wild plants, but pollinators, particularly bees, are globally declining as a result of various driving factors, including the prevalent use of pesticides for crop protection. Sublethal pesticide exposure negatively impacts numerous pollinator lifehistory traits, but its influence on reproductive success remains largely unknown. Such information is pivotal, however, to our understanding of the long-term effects on population dynamics.

2 We investigated the influence of field-realistic trace residues of the routinely used neonicotinoid insecticides thiamethoxam and clothianidin in nectar substitutes on the entire life-time fitness performance of the red mason bee Osmia bicornis.

3 We show that chronic, dietary neonicotinoid exposure has severe detrimental effects on solitary bee reproductive output. Neonicotinoids did not affect adult bee mortality; however, monitoring of fully controlled experimental populations revealed that sublethal exposure resulted in almost 50\% reduced total offspring production and a significantly male-biased offspring sex ratio.

4 Our data add to the accumulating evidence indicating that sublethal neonicotinoid effects on non-Apis pollinators are expressed most strongly in a rather complex, fitness-related context. Consequently, to fully mitigate long-term impacts on pollinator population dynamics, present pesticide risk assessments need to be expanded to include whole life-cycle fitness estimates, as demonstrated in the present study using $O$. bicornis as a model.
\end{abstract}

Keywords Clothianidin, fitness, neonicotinoid, Osmia, pesticide risk assessment, pollinator, population dynamics, sublethal effect, thiamethoxam.

\section{Introduction}

Pollinating insects contribute significantly to agricultural productivity (Klein et al., 2007; Garibaldi et al., 2011a), revenue (Gallai et al., 2009) and ecosystem stability (Bascompte et al., 2006; Fontaine et al., 2006), and are thus important components for the maintenance of biodiversity and food security. Recent reports on global pollinator declines (Biesmeijer et al., 2006; Potts et al., 2010; Cameron et al., 2011) are alarming, especially with respect to the currently high and continuously increasing demands for pollination services (Klein et al., 2007; Aizen et al., 2008).

Correspondence: Christoph Sandrock. e-mail: ch.sandrock@ gmail.com
Various managed and wild pollinators have been documented to exhibit similar population declines (Biesmeijer et al., 2006; Goulson et al., 2008; Potts et al., 2010), despite having different life histories and habitat requirements. This suggests the involvement of common primary drivers, such as emerging parasites and pathogens (Cameron et al., 2011; Nazzi et al., 2012), or habitat degradation (Potts et al., 2010; Garibaldi et al., 2011b). In addition, the prevalent use of pesticides in crop protection is also suspected to represent a conspicuous threat throughout agricultural landscapes (Desneux et al., 2007; Vanbergen \& The Insect Pollinator Initiative, 2013), particularly including the application of systemic neonicotinoid insecticides, which has increased strongly on a global scale over the last decade (Elbert et al., 2008; Mullin et al., 
2010; Jeschke et al., 2011). Neonicotinoids act as agonists of acetylcholine receptors in insects and other invertebrates, thereby disrupting neuromuscular signalling pathways, leading to abnormal behaviour, immobility and death of target insect pests (Matsuda et al., 2001; Elbert et al., 2008). Because neonicotinoids are systemic, nontarget pollinating insects can also be directly exposed to these compounds in flowering crops through the translocation of residue trace levels from vegetative plant parts into nectar and pollen, eventually causing detrimental sublethal effects (Desneux et al., 2007; Cresswell, 2011; Blacquière et al., 2012; Cresswell et al., 2012). For example, in honeybees, it was demonstrated that sublethal dietary exposure to neonicotinoids negatively affects learning abilities and memory, as well as foraging and homing behaviours (Decourtye et al., 2004; Decourtye \& Devillers, 2010; Belzunces et al., 2012; Henry et al., 2012; Williamson \& Wright, 2013). Moreover, there is increasing evidence of detrimental synergism when honeybees are exposed to a combination of neonicotinoids and the prevalent gut parasite Nosema sp. (Alaux et al., 2010; Vidau et al., 2011; Pettis et al., 2012) or viral pathogens (Di Prisco et al., 2013). To date, there is neither consensus on how to target and incorporate chronic and sublethal effect bioassays in pesticide risk assessment guidelines for the standard model organism, the honeybee (OEPP/EPPO, 2010a,b; Cresswell, 2011; Blacquière et al., 2012), nor any clear understanding of whether and how honeybee responses can be extrapolated to other pollinators exhibiting different life histories and foraging strategies (Desneux et al., 2007; Mommaerts et al., 2010; Biddinger et al., 2013). However, irrespective of the not yet fully understood causal mechanisms underlying specific aberrances after sublethal neonicotinoid exposure, it could be assumed that even subtle side-effects collectively come at a cost, which is likely to be translated into reduced fitness performance. Therefore, it is surprising that life-time reproductive success, the ultimate fitness endpoint, has received little attention in pesticide hazard evaluations (Desneux et al., 2007). Such information would not only be helpful for discovering yet unknown sublethal effects, but also is pivotal for understanding the long-term impact of insecticides on pollinator populations.

With regard to pesticide hazard evaluations, however, the honeybee might be a poor surrogate for pollinators in general because of its complex perennial life cycle, which leads to difficulties in quantifying reproductive success. Studies of pollinator species with annual and less complex life cycles could provide less ambiguous fitness quantifications. For example, in bumblebees (social bees with annual life cycles), it has been shown that chronic dietary exposure to field-realistic trace residues of imidacloprid strongly reduced colony performance and fitness (Mommaerts et al., 2010; Gill et al., 2012; Laycock et al., 2012; Whitehorn et al., 2012). In one semi-field study, Whitehorn et al. (2012) reported that 2 weeks of neonicotinoid exposure significantly decreased subsequent colony growth and vastly reduced daughter queen production; using a comparable experimental approach, very similar impacts on bumblebee colony fitness have recently been shown for clothianidin, another member of the neonicotinoids (Larson et al., 2013). The mechanistic factor contributing most to apparent decreases in fitness in chronically exposed bumblebee colonies under field conditions is considered to be a strongly impaired foraging performance and efficiency, as found similarly in laboratory and semifield studies (Mommaerts et al., 2010; Gill et al., 2012). This evidence clearly points to dietary neonicotinoid exposure having covert side-effects that are most likely expressed in relatively costly bumblebee life-history performances, such as reproductive investment, and that become most evident only under more realistic test conditions, which allow for the assessment of such informative endpoints (Cresswell et al., 2012). A similar indication of the complexity of the impact of neonicotinoids comes from the detrimental synergism observed in honeybees that were immune challenged with gut parasites (Alaux et al., 2010; Vidau et al., 2011; Pettis et al., 2012). In contrast to lethal poisoning incidences that result in readily visible and quantifiable mortality, sublethal effects of chronic insecticide exposure may rarely be recognized or masked by other factors in the field. If, however, sublethal effects of neonicotinoids can still trigger severely decreased output of daughter queens in bumblebees (Gill et al., 2012; Whitehorn et al., 2012; Larson et al., 2013), the consequences on local populations are probably comparable to the immediate lethal intoxication of large proportions of workers. This is because in bumblebees only young (mated) queens are capable of surviving winter and establishing new colonies in the next season. Hence, the question arises as to whether sublethal exposure to routinely applied insecticides could be contributing to general pollinator population declines by negatively impacting on reproductive fitness in a manner similar to that observed in experimental studies on bumblebees using neonicotinoids (Bryden et al., 2013).

Solitary bees represent an important species-rich group of wild pollinators providing crucial pollination services in both wild and crop plants (Klein et al., 2007; Winfree et al., 2007; Garibaldi et al., 2013). Surprisingly, solitary bees are virtually ignored in pesticide regulations (Blacquière et al., 2012). However, solitary bees represent much more convenient models for fitness quantification compared to social bees (honeybees and even bumblebees) because of the direct link between one individual female's performance and its reproductive success. Furthermore, detailed investigations of the impact of pesticides on solitary bees that differ in life-history traits (e.g. flight season, nesting habit, habitat and feeding specialization) would provide stronger and urgently needed insights into the wider environmental impacts of plant protection products.

The present study reports a novel methodological approach for quantifying the fitness effects of sublethal pesticide exposure on solitary bees under fully controlled experimental conditions. We assessed the impact of field-realistic dietary exposure to the neonicotinoids thiamethoxam and clothianidin on the life-time fitness performance of the red mason bee Osmia bicornis (syn. O. rufa, L. 1758; Hymenoptera, Megachilidae). We selected these particular neonicotinoids for two reasons. First, thiamethoxam is partly metabolized into clothianidin within plants (Maienfisch et al., 2001; Nauen et al., 2003), such that both neonicotinoids generally co-occurr in nectar and pollen of treated crops (Dively \& Kamel, 2012; Pohorecka et al., 2012). Second, in terms of sales, thiamethoxam is 
the second most important neonicotinoid after imidacloprid, and several commercially available formulations are routinely applied via foliar spraying or seed treatment for systemic protection in 115 crops from at least 65 countries worldwide (Elbert et al., 2008; Jeschke et al., 2011). The neonicotinoid concentrations that we used in the present study $(2.87 \mu \mathrm{g} / \mathrm{kg}$ for thiamethoxam and $0.45 \mu \mathrm{g} / \mathrm{kg}$ for clothianidin) were selected because they correspond to the range of field-realistic nectar residue-levels across several commonly treated crops in general (Blacquière et al., 2012). More particularly, they reflect residue levels after the systemic treatment of oilseed rape with thiamethoxam (Pohorecka et al., 2012), although considerably higher levels may be reached (e.g. in cucurbits after drip irrigation) (Dively \& Kamel, 2012; Stoner \& Eitzer, 2012).

The present study demonstrates that chronic sublethal neonicotinoid exposure of the solitary bee $O$. bicornis results in both strongly reduced reproductive success and male-biased offspring sex ratios. The bioassay has widespread value in that it can be readily adapted to laboratory, semi-field and field conditions, as well as be applied to other solitary bee species and, based on our findings, we urge that its principles be adopted in future pesticide risk assessment guidelines.

\section{Materials and methods}

\section{Study organism}

Osmia bicornis is a common above ground cavity-nesting megachilid species, native to Europe. It is univoltine, with a reproductive period from April to June, and uses a broad spectrum of floral resources. Although both males and females feed on flowers, it is exclusively the females who invest in brood care. Reproductive success depends on the female's ability to construct and provision brood cells with pollen, and to a lower extent also nectar, for progeny development. Females build nests in pre-made holes in wood or other structures, and sequentially construct linearly ordered brood cells separated by mud partitions. For the specific purpose of the present study, we used a whole population assessment, which is a natural situation because $O$. bicornis tends to be gregarious, with large nesting aggregations commonly observed in the field (Seidelmann, 2006; Seidelmann et al., 2010). Similar to many other solitary bees, O. bicornis exhibits a pronounced sexual dimorphism in body size. Males are smaller than females, and thus are less costly to produce because they need less food for larval development (Seidelmann, 2006; Seidelmann et al., 2010). Typically for hymenopterans, females have full control over offspring sex determination by regulating sperm release from the spermatheca for fertilization: fertilized eggs give rise to diploid daughters and unfertilized eggs result in haploid sons (Heimpel \& de Boer, 2008). Reproductive performance and sex allocation is influenced by the female's physiological conditions, such as body size and health. Larger females are able to produce more daughters as a result of their higher provisioning performance, which is demonstrated by their ability to forage more efficiently: they collect the same amount of pollen and nectar in a shorter time compared to smaller females (Seidelmann et al., 2010). Conversely, smaller females tend to shift their limited investment towards higher proportions of sons. In a similar manner, poor quality environments (e.g. weather, food plant abundance) that result in low provisioning efficiency, as well as the progressive senescence of reproducing females, lead to a reduced larval provisioning and a more pronounced investment in male offspring (Seidelmann, 2006; Seidelmann et al., 2010).

\section{Experimental set-up}

Rearing cages. The present study was conducted on two bee populations kept in two identical climate controlled rooms, equipped with a sunlight simulation system (maximum of $1000 \mu \mathrm{mol}$ photons $/ \mathrm{m}^{2} / \mathrm{s}$ ) and air conditioning (York International, Germany). Light, temperature and humidity were controlled in both rooms in parallel, simulating a natural climate, and this was kept constant throughout the experiment (Fig. 1). Each room contained a flight cage $(4.3 \times 2.4 \times 1.8 \mathrm{~m})$ built from white nylon mesh (1.33 mm mesh size; Wondermesh, U.K.). Both flight cages were designed to allow access of the experimenter but to prevent the escape of bees, and were equipped identically: nectar substitutes, pollen powder, nest tubes and nest substrates were provided and arranged in the same way and position for each cage, with each food and nesting material being obtained from the same supply. None of the material used in this experiment, except the pollen (see below), had been in contact with bees prior to the study.

Bee populations. To establish two breeding populations of O. bicornis, cocoons were purchased from WAB Mauerbienenzucht (Germany). All cocoons originated from the last nesting season, and from the same nesting site of a single source population; upon collection in the field during the previous autumn, cocoons were kept at $4{ }^{\circ} \mathrm{C}$, and then individually transferred to aerated containers at $22^{\circ} \mathrm{C}$ in early May to allow the bees to emerge. Upon hatching from cocoons, adult bees were sexed and assigned randomly to one of the two study populations until each contained 125 females and 75 males. All bees used in the experiment hatched within $24 \mathrm{~h}$ and were released simultaneously into each climate room (males first and females last). Prior to this release, all females were chilled after defecation for $5 \mathrm{~min}$ at $4{ }^{\circ} \mathrm{C}$ and weighed to the nearest $\mathrm{mg}$ on a Mettler AE260 (Mettler Toledo, Inc., Columbus, Ohio) and then individually marked with numbered honeybee tags. Mating activity occurred immediately after releasing the bees, and bees were able to forage and reproduce freely.

\section{Bee care and maintenance.}

1 Food: In each flight cage, nectar substitutes (50\% sugar content, containing equal amounts of glucose, fructose and sucrose; Hostettler's, Zurich, Switzerland) were provided $a d$ libitum in twelve artificial flowers. Each flower was built from $10-\mathrm{mL}$ laboratory plastic tubes (with closable lids) that were fixed upright to a small board hanging from the roof of the flight cage. At the bottom of each tube, a small piece of cardboard was fixed, serving as a landing place to 


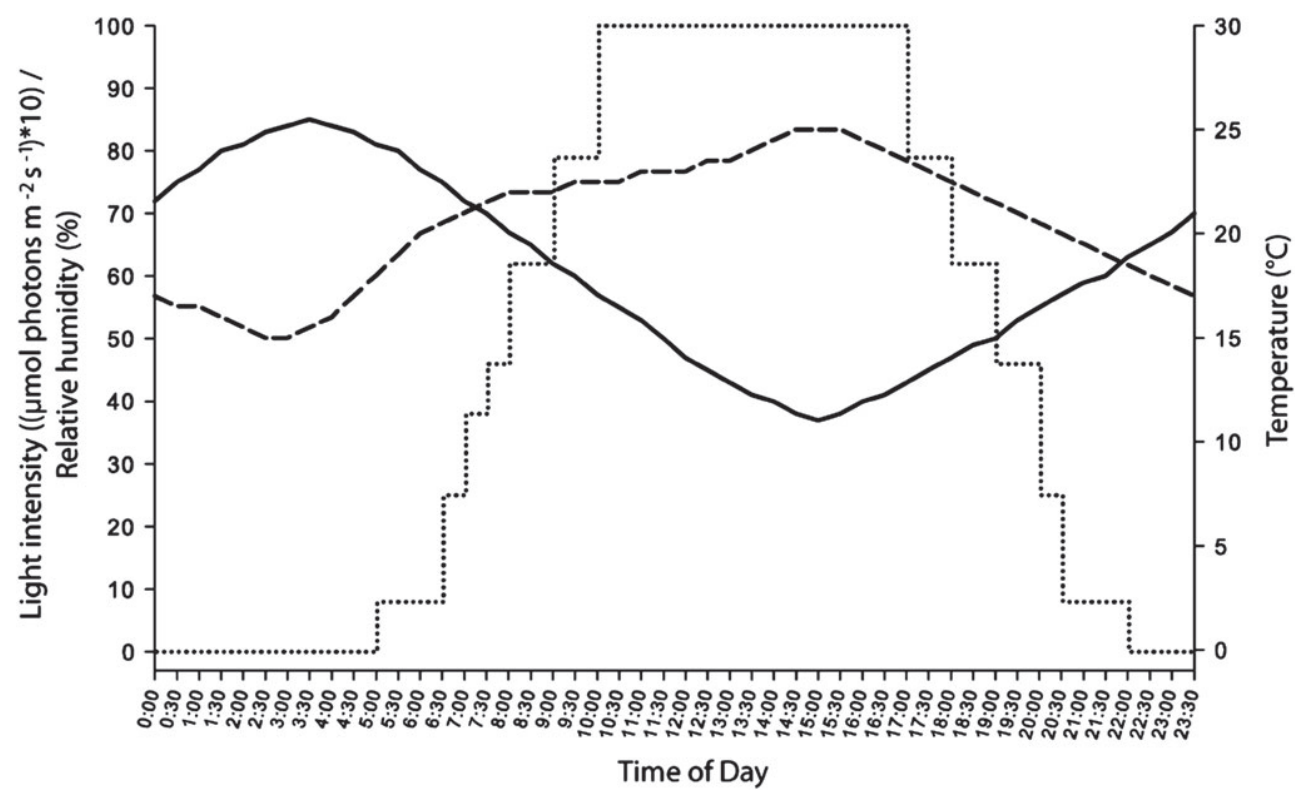

Figure 1 Climate simulation for the two study populations of Osmia bicornis. A computerized climate programme was run in both controlled environment rooms containing the bees and kept constant throughout the experiment. Light intensity (dotted line, left-hand $y$-axis) was adjusted stepwise, humidity (solid line, left-hand $y$-axis) and temperature (dashed line, right-hand $y$-axis) were adjusted gradually at 30-min intervals and are indicated for a 24-h period. Parameters were chosen to simulate a central European early summer day.

access nectar substitutes through two opposed holes (handmade, using a hot needle), just above the vessel bottom and sufficiently large to allow the tongue of the bees to enter (diameter $1 \mathrm{~mm}$ ). Attraction of bees to these artificial flowers was enhanced by simulating ultraviolet-reflective patterns using strips of commercial photographic paper, which were attached to the cardboard (landing place), as well as around the holes in the black lacquered tubes (see below). Artificial flowers were filled completely $(10 \mathrm{~mL})$ with freshly prepared nectar substitutes and were replaced every 3 days by new ones.

Bees in both flight cages were also provided with pollen, in the form of pulverized honeybee pollen pellets (one stock; Sonnentracht Imkerei, Germany). Microscopic examination of the pellets indicated that they contained pollen from at least 18 different floral resources. Pollen was gamma ray irradiated (Leoni Studer Hard AG, Däniken, Switzerland) to exclude honeybee pathogen spill-over effects. Four dishes containing pollen powder were placed in each flight cage, and their contents were replaced three times per day at intervals of $3-4 \mathrm{~h}$.

2 Nesting materials: Notched wooden boards that, when piled on top of each other, formed successive holes (diameter $8 \mathrm{~mm}$, length $16 \mathrm{~cm}$ ) (WAB Mauerbienenzucht) were used to build nesting blocks; each flight cage was provided with a total of 696 nest holes. The backsides of the blocks were sealed, and the fronts were painted with identical colour patterns. A mixture of commercial potter's clay and silica sand, offered in tilted plastic trays (volume of $6 \mathrm{~L}$ ), was provided as nesting substrate. Each tray contained a 250$\mathrm{mL}$ water tank from which two cloth wicks extended into the substrate to create a moisture gradient along which the bees could choose their preferred degree of wetted substrate. The tanks were covered with a mesh to prevent bees from drowning and were refilled each morning.

\section{Treatments and neonicotinoid residue analysis}

To simulate chronic insecticide exposure, the experimentally treated bee population differed from the control in that the nectar-substitute contained the neonicotinoids thiamethoxam and clothianidin.

Because neonicotinoids are very sensitive to direct (ultraviolet) light exposure (Maienfisch et al., 2001), artificial flowers were black-lacquered and covered with tinfoil to prevent nectar substitutes from direct exposure to the sunlight simulation system, as well as neonicotinoids from degradation. Pollen was not spiked with neonicotinoids because it could not be protected from light. Pure compounds (analytical standard; Fluka, Switzerland) were purchased from Sigma-Aldrich (Germany), dissolved in water, and stored at room temperature. Original sugar syrup and pollen stocks did not contain any of these chemicals (based on six random samples each). Sugar water was spiked using aliquots of neonicotinoid stock solutions to achieve concentrations of $2.87 \mu \mathrm{g} / \mathrm{kg}$ of thiamethoxam and $0.45 \mu \mathrm{g} / \mathrm{kg}$ of clothianidin, respectively; these concentrations were confirmed through residue analyses of random samples from each re-supply of nectar substitutes fed over the course of the experiment.

To determine neonicotinoid residue levels in current year's larval food provisions and offspring bees emerging in the subsequent year, from each flight cage (treatment and control populations), six samples of leftover larval provisions of ten nest cells each (from cells in which offspring failed to 
develop; see below) and six samples of ten newly-emerged, randomly picked adult offspring each were subjected to residue analyses. All analyses were performed by the United States Department of Agriculture, Agricultural Marketing Service National Standards Laboratory in Gastonia, North Carolina, using established methods. Individual samples were analyzed using gas chromatography (GC)-mass spectroscopy (MS) and applicable standards for both compounds with a limit of detection of 0.1 p.p.b. Identification of the parent compounds was based on co-chromatography with known standards using GC/MS and/or liquid chromatography/MS-MS.

\section{Data collection on bee fitness}

During the bee's flight activity season, we documented female mortality by inspecting flight cages daily for dead adult females. We similarly tracked the cumulative numbers of completed nests (i.e. nest entrances sealed by a nest plug).

Four weeks after all adult bees had died, climate programmes for the rooms were stopped and nest blocks were kept in darkness at $22^{\circ} \mathrm{C}$ for 4 months. Then, the nest blocks were separated to open the nest holes and to determine the number and conditions of nest contents. Both fully developed cocoons and undeveloped offspring were counted across all brood cells for each nest in each population. Leftover larval food provisions from undeveloped offspring were frozen for residue analysis (see above) and the cocoons were set aside and kept at $12{ }^{\circ} \mathrm{C}$ for 4 weeks and, subsequently, at $4{ }^{\circ} \mathrm{C}$ for 5 months. Furthermore, cocoons were then transferred to $22^{\circ} \mathrm{C}$ to estimate hatching success and sex ratios (per nest tube and overall). Finally, after emergence, body weights were documented for 101 randomly picked male and female offspring from each population.

\section{Statistical analysis}

Analyses were performed using R (R Core Development Team, 2011). To explicitly test for inequality in body weights of parental females in control and treatment populations based on the lowest detectable difference of $1 \mathrm{mg}$, we sorted body weights of females within groups and used a Wilcoxon signed rank test with continuity correction based on paired differences of body weight between bees assigned to the two different experimental populations. A generalized linear model (GLM) with gamma probability distribution was applied to test for a difference in mortality between populations. We tested for differences in the number of hatched offspring per nest between populations using a GLM with Poisson probability distribution. Proportional data of overall offspring mortality and daughters produced were compared using binomial tests. Offspring sex ratios inferred from individual nest tubes were analyzed with a GLM with binomial probability distribution. We tested for inequality in the central tendency, as well as for differences in distribution of offspring body weight between populations. A Wilcoxon signed rank test with continuity correction was used to assess whether the location shift in body weights between the groups of offspring deriving from different populations was different from zero. We also performed a Fligner-Killeen test for offspring body weight variance homogeneity between the populations. All analyses were conducted separately for females and males.

\section{Results}

\section{Neonicotinoid residue analysis}

None of the samples from either leftover larval food provisions or bees collected from the control and treatment populations contained detectable levels of thiamethoxam and clothianidin.

\section{Bee fitness}

Body weight distributions in founder females did not differ between the control and treatment population $(V=984$, $P<0.001)$.

Chronic exposure to field-realistic concentrations of thiamethoxam and clothianidin through nectar substitute had differing effects on the various fitness parameters.

There was no effect on adult females' longevity (Fig. 2 and Table 1): average life-spans reached in the treatment and control populations were $24.5 \pm 7.2$ and $23.8 \pm 6.6$ days, respectively. However, fewer nests were completed in the neonicotinoidtreated population: the control population completed 194 nests over the course of the breeding period, whereas the number in the treatment population was $22 \%$ lower (i.e. 151 nests) (Fig. 2). Further differences were evident with respect to brood cell number and larval mortality rate. Completed nests in the treatment population contained $43.7 \%$ fewer total brood cells than the control (i.e. 497 compared to 883). In addition, relative offspring mortality was almost two-fold higher in the treatment population; the proportion of offspring that completed larval development and/or were able to hatch after hibernation was thus lower compared to the control (i.e. 423 in the treatment population compared to 808 in the control $)\left(\chi^{2}=12.85\right.$, d.f. $=1, P<0.001$ ), corresponding to $15 \%$ and $8.5 \%$ mortality, respectively. Overall, chronic exposure to neonicotinoids had a significant negative effect on the number of offspring that emerged per nest (Fig. 3 and Table 1).

Table 1 Summary of the results of the generalized linear models (GLM) performed to evaluate the effect of chronic exposure to neonicotinoids (thiamethoxam and clothianidin) on adult mortality, the number of cocoons per nest tube and offspring sex ratios of the red mason bee Osmia bicornis

\begin{tabular}{|c|c|c|c|c|}
\hline GLM & Parameter & Estimate & SE & $P$-value \\
\hline Mortality & Intercept & 0.042 & 0.001 & $<0.001$ \\
\hline $\begin{array}{l}\text { Gamma probability } \\
\text { distribution }\end{array}$ & Neonicotinoids & -0.001 & 0.001 & 0.481 \\
\hline Number of cocoons per tube & Intercept & 1.427 & 0.035 & $<0.001$ \\
\hline $\begin{array}{l}\text { Poisson probability } \\
\text { distribution }\end{array}$ & Neonicotinoids & -0.397 & 0.06 & $<0.001$ \\
\hline Offspring sex ratio & Intercept & 0.224 & 0.071 & 0.002 \\
\hline $\begin{array}{l}\text { Binomial probability } \\
\text { distribution }\end{array}$ & Neonicotinoids & -0.342 & 0.12 & 0.004 \\
\hline
\end{tabular}

Parameter estimates and SEs are given on the relative, canonical link scale. For details, see Materials and methods. 


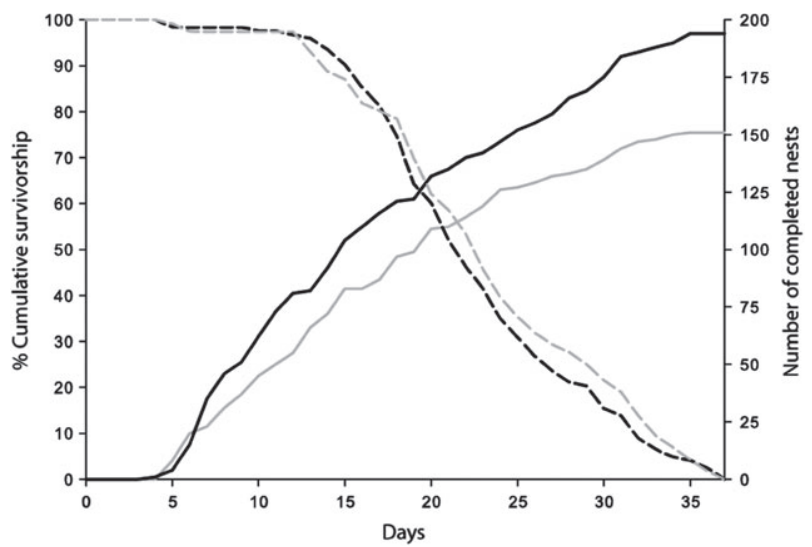

Figure 2 Cumulative survivorship and numbers of completed nest tubes. Dashed lines represent the percentage of cumulative survivorship of individually marked Osmia bicornis females (left-hand $y$-axis) plotted against time for the control bees (black) and treatment bees chronically exposed to neonicotinoids (grey). Mortality rates (measured as time-todeath) did not differ between the two bee groups $(P=0.481)$ (Table 1). Solid lines represent the cumulative numbers of completed nest tubes (right-hand $y$-axis) for the control bees (black) and treatment bees (grey). The treatment population completed 151 nests in total (i.e. 22\% less than the 194 nests in the control population).

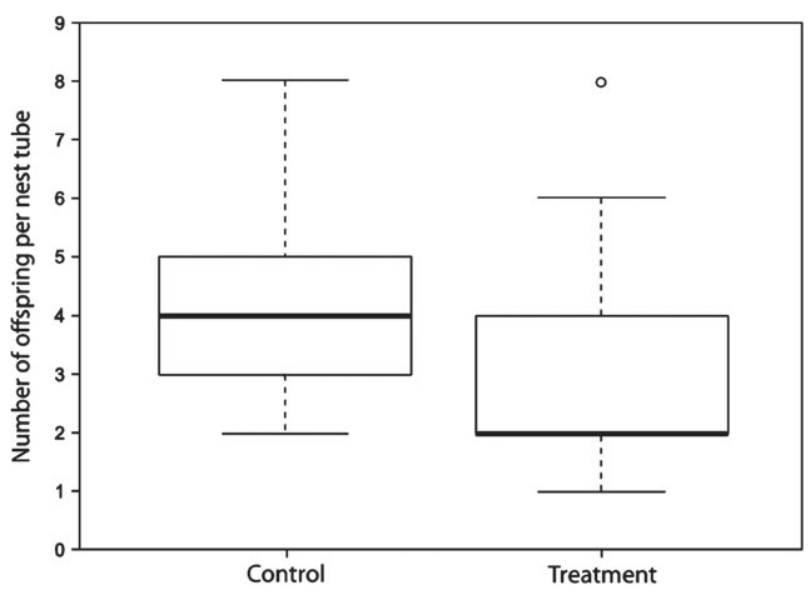

Figure 3 Number of offspring per nest tube. The numbers of offspring that hatched per nest tube are shown for the control and treatment populations of Osmia bicornis. Thick horizontal lines represent medians, boxes indicate $25-75$ th percentile range, and whiskers show the total range of the data (outliers are given as circles). Mean \pm SD numbers of hatched offspring per nest were $4.17 \pm 1.58$ for the control population and $2.80 \pm 1.46$ for the treatment population. Chronic exposure to neonicotinoids (thiamethoxam and clothianidin) had a significant negative effect on the total number of hatched offspring per nest tube $(P<0.001)$ (Table 1) compared to the control bees.

Significantly male-biased offspring sex ratios were detected across nests within the treatment population (Table 1), resulting in a significantly lower proportion of daughters overall $\left(\chi^{2}=7.75\right.$, d.f. $\left.=1, \quad P<0.003\right)$ compared to the control population. On average, $47.1 \%$ of emerged bees in the treatment population and $55.6 \%$ of bees in the control population were females.

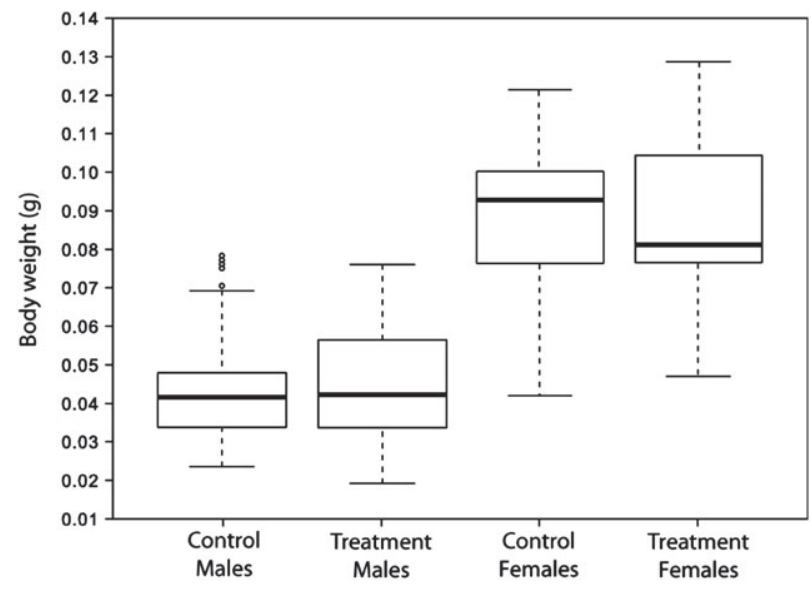

Figure 4 Offspring body weights. Body weight distributions of adult offspring are shown for the control and treatment populations of Osmia bicornis, based on 101 randomly picked individuals of each sex per population. Thick horizontal lines represent medians, boxes indicate $25-75$ th percentile range, and whiskers show the total range of the data (outliers are given as circles). Mean $\pm S D$ values for males: $42.7 \pm 12.5 \mathrm{mg}$ (control) and $45.2 \pm 12.8 \mathrm{mg}$ (treatment), and for females: $88.6 \pm 18.8 \mathrm{mg}$ (control) and $87.6 \pm 18.8 \mathrm{mg}$ (treatment). For each sex, offspring body weight distributions neither differed, nor varied significantly between the experimental populations.

Taken together, the treatment population produced $47.7 \%$ fewer offspring, including a $8.5 \%$ lower proportion of daughters, compared to the control population. The total numbers of female offspring in the treatment and control populations, with 199 versus 449 daughters, respectively, reveal a 2.3-fold reduced population growth upon chronic neonicotinoid exposure.

Emerged offspring from the two different populations, however, did not differ with respect to mean body weight (females: $W=5496.5, \quad P=0.341 ;$ males: $W=4694.5, \quad P=0.329$ ) (Fig. 4) or body weight variance (females: $\chi^{2}=97.8$, d.f. $=90$, $P=0.269$; males: $\chi^{2}=100$, d.f. $\left.=95, P=0.434\right)$.

\section{Discussion}

The present study aimed to develop a feasible experimental procedure for quantifying the side-effects of chronic pesticide exposure on the life-time reproductive success of a representative of an important group of pollinators, solitary bees, which so far remain unconsidered in risk assessment guidelines. The results obtained reveal some major impacts on the red mason bee O.bicornis from low-level exposure to prevalent neonicotinoids. More specifically, we contribute data that strengthen our knowledge base regarding the ongoing debate on how widespread neonicotinoid applications in systemic crop protection could be influencing recent pollinator declines, and that point to the inclusion of solitary bees in future assessments.

Our findings show that while dietary exposure to fieldrealistic trace residues of two neonicotinoids, thiamethoxam and clothianidin, had no impact on the mortality of the actively foraging adult bees (Fig. 2), with mean longevities similar to those observed in the field (Seidelmann, 2006), 
it significantly impacted the $F_{1}$ generation. Indeed, chronic sublethal exposure to less than $3.5 \mu \mathrm{g} / \mathrm{kg}$ neonicotinoids in nectar substitutes had marked negative consequences on the fitness performance of bees: while the nest building rate of non-exposed females approximated that reported in the field (Seidelmann et al., 2010), exposed female bees both completed fewer nests and constructed fewer brood cells per nest (Fig. 3 and Table 1), thus exhibiting a reduction in offspring production of almost 50\%. Moreover, while the offspring sex ratios of non-exposed females with more than $50 \%$ daughters indicate good environmental conditions, neonicotinoid exposure resulted in significantly male-biased offspring sex ratios (Table 1), thus further compounding the overall loss of reproductive potential. Our findings concur with recent studies on bumblebees, where dietary exposure to environmentally relevant residues of the neonicotinoids imidacloprid and clothianidin caused decelerated colony growth and a decrease of $85-100 \%$ in daughter queen production (Gill et al., 2012; Whitehorn et al., 2012; Larson et al., 2013). These results reveal that neonicotinoid exposure has covert side effects that can negatively affect reproductive success and long-term population dynamics, and also that these effects can occur across different genera of wild bees.

Given that systemic neonicotinoids are broadly used to combat pests on various pollinator-attractive crops, red mason bees and related species found in agricultural landscapes could be chronically exposed to these chemicals during most of their breeding period, or even whole life cycles, as simulated in the present study. Members of the genus Osmia are generalist in their flower visitation and feed on a variety of floral resources, and common mass-flowering crops are readily incorporated into their diet (Westphal et al., 2003; Jauker et al., 2012; Holzschuh et al., 2013). Although foraging in the field likely includes alternative resources, generalist bees such as $O$. bicornis commonly exploit mainly high-reward mass-flowering plants to maximize foraging efficiency (Westphal et al., 2003; Winfree et al., 2007; Teper \& Biliński, 2009; Radmacher \& Strohm, 2010). Of special concern is that the breeding season of $O$. bicornis includes the flowering period of oilseed rape, which can contribute considerable proportions of this species' nutrition, even if alternatives are available (Teper \& Biliński, 2009; Holzschuh et al., 2013), and which is most often treated with neonicotinoids. There could be additional exposure routes to neonicotinoids for noncrop plants, for example, via dust drift during drilling of coated seeds and its deposition on flowering weeds in the surroundings of agricultural areas (Krupke et al., 2012).

Although our reported findings on sublethal neonicotinoid effects provide evidence of potentially severe impacts on solitary bee populations, the present study was conducted in a laboratory setting, and our conclusions need to be replicated in the field. However, our results are biologically important and carry strong weight for four reasons. First, the chosen set-up and procedures minimized the chance that there could have been undetected factors of either biological or mechanical nature influencing both populations differently: it can be assumed that the control and the treatment population did not differ with respect to their genetic background, nor with respect to the a priori conditions of the founder females, which could have influenced reproductive performance and offspring sex allocation, and that climate simulations, as well as the equipment in both flight cages, were identical.

Second, the fact that mortality rates did not differ between the control and treated populations (Fig. 2) makes it very unlikely that the effects from individual females interacting in a nonindependent manner could have differed between populations, which furthermore had approximately equal numbers of adult females. Thus, the populations differed only with respect to the presence or absence of neonicotinoids. Third, equal mortality rates and longevities are indicative of the absence of repellence and anti-feeding effects of the applied environmentally relevant concentrations of neonicotinoids, as previously reported for honeybees and bumblebees (Faucon et al., 2005; Gill et al., 2012). Finally, the presence of any undetected factors, such as microbial infections, can be assumed to have been similar in both populations because all randomly allocated bees originated from the same source.

Considering the general mode of neurotoxic action of neonicotinoids in insects (Matsuda et al., 2001; Desneux et al., 2007), toxicological effects resulting in behavioural, cognitive or locomotive abnormalities could result in the devastating fitness response reported in the present study in solitary bees and previously in bumblebees (Whitehorn et al., 2012). Physiological functions are tightly integrated with the nervous system of a bee (Belzunces et al., 2012). Therefore, even subtle impairments of manifold fundamental mechanisms could collectively limit basic tasks, such as foraging performance (Cresswell et al., 2012; Gill et al., 2012; Henry et al., 2012), and these have been suggested to explain the decelerated colony growth and lower reproductive success in bumblebees (Mommaerts et al., 2010; Whitehorn et al., 2012). Compared to honeybee colonies, which are perennial and consist of several thousands of workers exhibiting a complex division of labour, with a high degree of adaptive plasticity and generally high turn-over rates, bumblebees, which are also social bees but with small-sized colonies and annual life-cycles, appear to express sublethal effects more strongly (Gill et al., 2012; Whitehorn et al., 2012). The present study provides the first evidence suggesting that the same applies to solitary bees, as exemplified by the red mason bee $O$. bicornis .

In this species, reduced provisioning efficiency has been shown to result in decreased numbers of brood cells per nest, as well as male-biased offspring sex ratios (Seidelmann et al., 2010), with both effects being observed in the present study in bees exposed to neonicotinoids. These shifts in breeding and offspring sex allocation strategies have mainly been attributed to evolutionary adaptations in mitigating brood parasitism (Seidelmann, 2006). Decreased foraging efficiency, as commonly induced by poor environments, high travelling costs or as an effect of female senescence, translates into an increased provisioning time per brood cell, which is positively correlated with a higher risk of brood parasitism. Accordingly, reduced numbers of offspring per nest and an apparent shift in offspring sex allocation towards less costly sons represent reliable general responses in reproductive investment to maximize fitness under adverse conditions in this and other solitary bee species (Seidelmann et al., 2010). The fact that our findings on O. bicornis exposed to sublethal neonicotinoid dosages reflect 
these patterns exactly (Figs 2 and 3 and Table 1) leads us to interpret them as most likely resulting from an overall impaired foraging performance and provisioning efficiency, as also demonstrated in several studies on bumblebees (Mommaerts et al., 2010; Gill et al., 2012; Whitehorn et al., 2012) and honeybees (Cresswell, 2011; Belzunces et al., 2012; Henry et al., 2012; Schneider et al., 2012).

With respect to the male-biased offspring sex ratios that we observed in $O$. bicornis, neonicotinoids may also have additional negative consequences in hymenopterans. In this order of insects, egg fertilization depends on the female voluntarily releasing stored sperm from her spermatheca (i.e. from where they are stored) (van Wilgenburg et al., 2006) and neonicotinoids might directly impact this active process. Indeed, male-biased offspring sex ratios were reported for parasitoid wasps exposed to neurotoxic insecticides (Desneux et al., 2007), which suggests that this may occur in other solitary hymenopterans. The putative effects of sublethal neonicotinoid exposure on egg fertilization in haplodiploid nontarget insects thus deserve further research.

An important point raised by our data is indicated by the negative effects that we observed on offspring survival in the neonicotinoid-exposed population. Although mortality rates in both study populations can be considered to be in the range of what might be expected in the field (when referring to mortality that is not caused by parasitizing arthropods, as was the case in the present study) (Seidelmann et al., 2010), the difference between them was significant. Given that offspring body weight is strongly correlated with the amount of larval provisioning, which decreases with reduced foraging efficiency (Seidelmann, 2006; Seidelmann et al., 2010), partially insufficient food provisioning by the mothers could have caused the lower offspring survivorship in our neonicotinoid-exposed population, and also could have contributed to biased offspring sex ratios if female offspring, requiring more food, were more likely to fail during development compared to males. However, offspring body weight means and variances of both sexes did not differ between the treatment and control populations (Fig. 4), which suggests that there were comparable amounts of food provision in the two populations. Therefore, when directly comparing mortality rates of the populations, it is possible that the restricted offspring development evident in our treatment population was a direct consequence of the neonicotinoids in the nectar substitutes. If exposure to neonicotinoids did impact bee development, this would suggest that the larval stages of $O$. bicornis are more sensitive than adults because we spiked only the nectar; in adults, nectar is a major food but it constitutes only a very small proportion of the larval food provisions of O. bicornis (Strohm et al., 2002), which explains why we did not find any traceable amounts of either neonicotinoid in the larval provision samples subjected to residue analyses. In a field setting, the impact of neonicotinoids could be much higher than we observed because broods of solitary bees would be exposed to higher levels of neonicotinoids as a result of their feeding on pollen, which, in crops treated systemically with neonicotinoids, generally contains higher concentrations than nectar (Blacquière et al., 2012; Dively \& Kamel, 2012). Thus, we can expect solitary bee larvae in the field to commonly ingest greater quantities of neonicotinoids than did our laboratory-reared offspring.

It is very noteworthy that our findings regarding the impact of neonicotinoids in solitary bees are similar to those obtained in a separate investigation on bumblebees by Whitehorn et al. (2012), even though the two studies differed markedly in experimental set-up: in both, there was a reduction in numbers of female offspring upon field-realistic neonicotinoid exposure, implicating long-term impacts on effective population size. This impact is critical to population stability because small populations are more vulnerable to stochastic environmental processes and inbreeding depression (Goulson et al., 2008). Of special relevance to bees, inbreeding depression can result in detrimental diploid male production instead of female offspring as a result of their complementary sex determination system (Zayed \& Packer, 2005; Heimpel \& de Boer, 2008; Whitehorn et al., 2009; Darvill et al., 2012). Assuming that the outcomes of both our study and that of Whitehorn et al. (2012), where reproductive output (offspring numbers) barely replaced parental females, can be extrapolated to field settings, it becomes clear that sublethal chronic neonicotinoid exposure could have a major impact on pollinator populations.

Dispersal and gene flow among populations of wild pollinators could counterbalance locally occurring detrimental effects as a result of neonicotinoid exposure. Yet, regarding the present dimensions of systemic neonicotinoid applications (Blacquière et al., 2012), at some point, recurrent fitness losses in agricultural landscapes may fail to be compensated by functional metapopulation networks facing additional adverse conditions such as habitat degradation, emerging parasites or climate change (Goulson et al., 2008; Potts et al., 2010). Wild pollinator population declines are not only of concern for biodiversity, but also for food security (Garibaldi et al., 2013). In the light of continuing honeybee losses (Winfree et al., 2007; Aizen et al., 2008; Aizen \& Harder, 2009; Potts et al., 2010; Pettis et al., 2012), red mason bees and several related species are increasingly being established for managed pollination services (Bosch \& Kemp, 2002; Teper \& Biliński, 2009; Jauker et al., 2012) to counteract suspected declines in crop pollination services. The sustainability of their use depends on the minimization of bee exposure to long-term sublethal environmental stressors, such as neonicotinoids.

In conclusion, our study of the solitary bee $O$. bicornis and several studies of bumblebees (Gill et al., 2012; Whitehorn et al., 2012; Larson et al., 2013) concordantly demonstrate a link between chronic sublethal neonicotinoid exposure and reduced life-time reproductive success. Of crucial importance, these findings indicate that the current mandatory guidelines for pesticide risk assessment (i.e. the tiered approach of testing for side-effects of plant protection products on honeybees only) (OECD, 1998a, b; OEPP/EPPO, 2010a, b), is insufficient to ensure ecological sustainability for pollinators in a broad sense. Referring to the recently published guidance document by the European Food Safety Authority (http://www.efsa.europa.eu/en/efsajournal/doc/3295.pdf), the hazard evaluation schemes for pesticide regulations should urgently implement more stringent testing of sublethal and chronic effects on pollinators in general, and critically consider entire life-cycle fitness assessments of selected non-Apis 
pollinators, such as the assay reported in the present study using the solitary bee $O$. bicornis.

\section{Acknowledgements}

We are grateful to Matthias Volk at Agroscope ReckenholzTänniken, ART, for providing research facilities, technical support and discussions, as well as Robin Dean and Roger Konrad for advice concerning the experimental procedures. We thank Mike Herrmann for helpful suggestions and providing Osmia cocoons, as well as five anonymous reviewers for their constructive comments on the manuscript. This research received funding from the European Union Framework 7 under grant agreement no. 244090 (CP-FP) STEP (Status and Trends in European Pollinators).

\section{References}

Aizen, M.A. \& Harder, L.D. (2009) The global stock of domesticated honey bees is growing slower than agricultural demand for pollination. Current Biology, 19, 915-918.

Aizen, M.A., Garibaldi, L.A., Cunningham, S.A. \& Klein, A.M. (2008) Long-term global trends in crop yield and production reveal no current pollination shortage but increasing pollinator dependency. Current Biology, 18, 1572-1575.

Alaux, C., Brunet, J.L., Dussaubat, C., Mondet, F. et al. (2010) Interactions between Nosema microspores and a neonicotinoid weaken honeybees (Apis mellifera). Environmental Microbiology, 12, 774-782.

Bascompte, J., Jordano, P. \& Olesen, J.M. (2006) Asymmetric coevolutionary networks facilitate biodiversity maintenance. Science, 312, 431-433.

Belzunces, L.P., Tchamitchan, S. \& Brunet, J. (2012) Neural effects of insecticides in the honey bee. Apidologie, 43, 348-370.

Biddinger, D.J., Robertson, J.L., Mullin, C. et al. (2013) Comparative toxicities and synergism of apple orchard pesticides to Apis mellifera (L.) and Osmia cornifrons (Radoszkowski). PLoS One, 8, e72587.

Biesmeijer, J.C., Roberts, S.P.M., Reemer, M. et al. (2006) Parallel declines in pollinators and insect-pollinated plants in Britain and the Netherlands. Science, $\mathbf{3 1 3}, 351-354$.

Blacquière, T., Smagghe, G., van Gestel, C.A. \& Mommaerts, V. (2012) Neonicotinoids in bees: a review on concentrations, side-effects and risk assessment. Ecotoxicology, 21, 973-992.

Bosch, J. \& Kemp, W.P. (2002) Developing and establishing bee species as crop pollinators: the example of Osmia spp. (Hymenoptera: Megachilidae) and fruit trees. Bulletin of Entomological Research, 92, 3-16.

Bryden, J., Gill, R.J., Mitton, R.A., Raine, N.E. \& Jansen, V.A. (2013) Chronic sublethal stress causes bee colony failure. Ecology Letters, 16, 1463-1469.

Cameron, S.A., Lozier, J.D., Strange, J.P., Koch, J.B., Cordes, N., Solter, L.F. \& Griswold, T.L. (2011) Patterns of widespread decline in North American bumble bees. Proceedings of the National Academy of Sciences of the United States of America, 108, 662-667.

Cresswell, J.E. (2011) A meta-analysis of experiments testing the effects of a neonicotinoid insecticide (imidacloprid) on honey bees. Ecotoxicology, 20, 149-157.

Cresswell, J.E., Desneux, N. \& van Engelsdorp, D. (2012) Dietary traces of neonicotinoid pesticides as a cause of population declines in honey bees: an evaluation by Hill's epidemiological criteria. Pest Management Science, 68, 819-827.
Darvill, B., Lepais, O., Woodall, L.C. \& Goulson, D. (2012) Triploid bumblebees indicate a direct cost of inbreeding in fragmented populations. Molecular Ecology, 21, 3988-3995.

Decourtye, A. \& Devillers, J. (2010). Ecotoxicity of neonicotinoid insecticides to bees. Insect Nicotinic Acetylcholine Receptors, 1st edn (ed. by S. H. Thany), pp. 85-95. Springer, New York, New York.

Decourtye, A., Devillers, J., Cluzeau, S., Charreton, M. \& PhamDelegue, M.H. (2004) Effects of imidacloprid and deltamethrin on associative learning in honeybees under semi-field and laboratory conditions. Ecotoxicology and Environmental Safety, 57, 410-419.

Desneux, N., Decourtye, A. \& Delpuech, J.M. (2007) The sublethal effects of pesticides on beneficial arthropods. Annual Review of Entomology, 52, 81-106.

Di Prisco, G., Cavaliere, V., Annoscia, D. et al. (2013) Neonicotinoid clothianidin adversely affects insect immunity and promotes replication of a viral pathogen in honey bees. Proceedings of the National Academy of Sciences of the United States of America, in press. doi: 10.1073/pnas.1314923110.

Dively, G.P. \& Kamel, A. (2012) Insecticide residues in pollen and nectar of a cucurbit crop and their potential exposure to pollinators. Journal of Agricultural and Food Chemistry, 60, 4449-4456.

Elbert, A., Haas, M., Springer, B., Thielert, W. \& Nauen, R. (2008) Applied aspects of neonicotinoid uses in crop protection. Pest Management Science, 64, 1099-1105.

Faucon, J.P., Aurieres, C., Drajnudel, P. et al. (2005) Experimental study on the toxicity of imidacloprid given in syrup to honey bee (Apis mellifera) colonies. Pest Management Science, 61, 111-125.

Fontaine, C., Dajoz, I., Meriguet, J. \& Loreau, M. (2006) Functional diversity of plant-pollinator interaction webs enhances the persistence of plant communities. PLoS Biology, 4, e1.

Gallai, N., Salles, J.M., Settele, J. \& Vaissiere, B.E. (2009) Economic valuation of the vulnerability of world agriculture confronted with pollinator decline. Ecological Economics, 68, 810-821.

Garibaldi, L.A., Aizen, M.A., Klein, A.M., Cunningham, S.A. \& Harder, L.D. (2011a) Global growth and stability of agricultural yield decrease with pollinator dependence. Proceedings of the National Academy of Sciences of the United States of America, 108, 5909-5914.

Garibaldi, L.A., Steffan-Dewenter, I., Kremen, C. et al. (2011b) Stability of pollination services decreases with isolation from natural areas despite honey bee visits. Ecology Letters, 14, 1062-1072.

Garibaldi, L.A., Steffan-Dewenter, I., Winfree, R. et al. (2013) Wild pollinators enhance fruit set of crops regardless of honey bee abundance. Science, 339, 1608-1611.

Gill, R.J., Ramos-Rodriguez, O. \& Raine, N.E. (2012) Combined pesticide exposure severely affects individual- and colony-level traits in bees. Nature, 491, 105-108.

Goulson, D., Lye, G.C. \& Darvill, B. (2008) Decline and conservation of bumble bees. Annual Review of Entomology, 53, 191-208.

Heimpel, G.E. \& de Boer, J.G. (2008) Sex determination in the Hymenoptera. Annual Review of Entomology, 53, 209-230.

Henry, M., Beguin, M., Requier, F. et al. (2012) A common pesticide decreases foraging success and survival in honey bees. Science, 336, $348-350$.

Holzschuh, A., Dormann, C.F., Tscharntke, T. \& Steffan-Dewenter, I. (2013) Mass-flowering crops enhance wild bee abundance. Oecologia, 172, 477-484.

Jauker, F., Bondarenko, B., Becker, H.C. \& Steffan-Dewenter, I. (2012) Pollination efficiency of wild bees and hoverflies provided to oilseed rape. Agricultural and Forest Entomology, 14, 81-87.

Jeschke, P., Nauen, R., Schindler, M. \& Elbert, A. (2011) Overview of the status and global strategy for neonicotinoids. Journal of Agricultural and Food Chemistry, 59, 2897-2908.

Klein, A.M., Vaissière, B.E., Cane, J.H., Steffan-Dewenter, I., Cunningham, S.A., Kremen, C. \& Tscharntke, T. (2007) Importance of 
pollinators in changing landscapes for world crops. Proceedings of the Royal Society B: Biological sciences, 274, 303-313.

Krupke, C.H., Hunt, G.J., Eitzer, B.D., Andino, G. \& Given, K. (2012) Multiple routes of pesticide exposure for honey bees living near agricultural fields. PLoS One, 7, e29268.

Larson, J.L., Redmond, C.T. \& Potter, D.A. (2013) Assessing insecticide hazard to bumble bees foraging on flowering weeds in treated lawns. PLoS One, 8, e66375.

Laycock, I., Lenthall, K.M., Barratt, A.T. \& Cresswell, J.E. (2012) Effects of imidacloprid, a neonicotinoid pesticide, on reproduction in worker bumble bees (Bombus terrestris). Ecotoxicology, 21, 1937-1945.

Maienfisch, P., Angst, M., Brandl, F. et al. (2001) Chemistry and biology of thiamethoxam: a second generation neonicotinoid. Pest Management Science, 57, 906-913.

Matsuda, K., Buckingham, S.D., Kleier, D., Rauh, J.J., Grauso, M. \& Sattelle, D.B. (2001) Neonicotinoids: insecticides acting on insect nicotinic acetylcholine receptors. Trends in Pharmacological Sciences, 22, 573-580.

Mommaerts, V., Reynders, S., Boulet, J., Besard, L., Sterk, G. \& Smagghe, G. (2010) Risk assessment for side-effects of neonicotinoids against bumblebees with and without impairing foraging behavior. Ecotoxicology, 19, 207-215.

Mullin, C.A., Frazier, M., Frazier, J.L., Ashcraft, S., Simonds, R., van Engelsdorp, D. \& Pettis, J.S. (2010) High levels of miticides and agrochemicals in North American apiaries: implications for honey bee health. PLoS One, 5, e9754.

Nauen, R., Ebbinghaus-Kintscher, U., Salgado, V.L. \& Kaussmann, M. (2003) Thiamethoxam is a neonicotinoid precursor converted to clothianidin in insects and plants. Pesticide Biochemistry and Physiology, 76, 55-69.

Nazzi, F., Brown, S.P., Annoscia, D. et al. (2012) Synergistic parasite-pathogen interactions mediated by host immunity can drive the collapse of honeybee colonies. PLoS Pathogens, 8, e1002735.

OECD (1998a) Test No. 213: Honeybees, Acute Oral Toxicity. OECD Guidelines for the testing of chemicals. Section 2, Effects on Biotic Systems. OECD Publishing, Paris.

OECD (1998b) Test No. 214: Honeybees, Acute Contact Toxicity Test. OECD Guidelines for the testing of chemicals. Section 2, Effects on Biotic Systems. OECD Publishing, Paris.

OEPP/EPPO (2010a) EPPO Standards PP1/170 (4) Efficacy evaluation of plant protection products. Side-effects on honeybees. Bulletin OEPP/EPPO, 31, 313-319.

OEPP/EPPO (2010b) EPPO Standards PP 3/10 (3) Environmental risk assessment for plant protection products. Chapter 10: honeybees. Bulletin OEPP/EPPO, 40, 323-331.

Pettis, J.S., van Engelsdorp, D., Johnson, J. \& Dively, G. (2012) Pesticide exposure in honey bees results in increased levels of the gut pathogen Nosema. Naturwissenschaften, 99, 153-158.

Pohorecka, K., Skubida, P., Miszczak, A. et al. (2012) Residues of neonicotinoid insecticides in bee collected plant materials from oilseed rape crops and their effect on bee colonies. Journal of Apicultural Science, 56, 5-24.

Potts, S.G., Biesmeijer, J.C., Kremen, C., Neumann, P., Schweiger, O. \& Kunin, W.E. (2010) Global pollinator declines: trends, impacts and drivers. Trends in Ecology \& Evolution, 25, 345-353.
Radmacher, S. \& Strohm, E. (2010) Factors affecting offspring body size in the solitary bee Osmia bicornis (Hymenoptera, Megachilidae). Apidologie, 41, 169-177.

R Core Development Team (2011) R: A Language and Environment for Statistical Computing [WWW document]. URL http://www.rproject.org [accessed 21 September 2012].

Schneider, C.W., Tautz, J., Grünewald, B. \& Fuchs, S. (2012) RFID tracking of sublethal effects of two neonicotinoid insecticides on the foraging behavior of Apis mellifera. PLoS One, 7, e30023.

Seidelmann, K. (2006) Open-cell parasitism shapes maternal investment patterns in the red mason bee Osmia rufa. Behavioral Ecology, 17, 839-848.

Seidelmann, K., Ulbrich, K. \& Mielenz, N. (2010) Conditional sex allocation in the Red Mason bee, Osmia rufa. Behavioral Ecology and Sociobiology, 64, 337-347.

Stoner, K.A. \& Eitzer, B.D. (2012) Movement of soil-applied imidacloprid and thiamethoxam into nectar and pollen of squash (Cucurbita pepo). PLoS One, 7, e39114.

Strohm, E., Daniels, H., Warmers, C. \& Stoll, C. (2002) Nest provisioning and a possible cost of reproduction in the megachilid bee Osmia rufa studied by a new observation method. Ethology Ecology and Evolution, 14, 255-268.

Teper, D. \& Biliński, M. (2009) Red Mason bee (Osmia rufa L.) as a pollinator of rape plantations. Journal of Apicultural Science, $\mathbf{5 3}$, 115-119.

Vanbergen, A.J. \& The Insect Pollinator Initiative (2013) Threats to an ecosystem service: pressures on pollinators. Frontiers in Ecology and the Environment, 11, 251-259.

Vidau, C., Diogon, M., Aufauvre, J. et al. (2011) Exposure to sublethal doses of fipronil and thiacloprid highly increases mortality of honeybees previously infected by Nosema ceranae. PLoS One, 6, e21550.

Westphal, C., Steffan-Dewenter, I. \& Tscharntke, T. (2003) Mass flowering crops enhance pollinator densities at a landscape scale. Ecology Letters, 6, 961-965.

Whitehorn, P.R., Tinsley, M.C., Brown, M.J., Darvill, B. \& Goulson, D. (2009) Impacts of inbreeding on bumblebee colony fitness under field conditions. BMC Evolutionary Biology, 9, 152.

Whitehorn, P.R., O'Connor, S., Wackers, F.L. \& Goulson, D. (2012) Neonicotinoid pesticide reduces bumble bee colony growth and queen production. Science, 336, 351-352.

van Wilgenburg, E., Driessen, G. \& Beukeboom, L.W. (2006) Single locus complementary sex determination in Hymenoptera: an 'unintelligent' design? Frontiers in Zoology, 3, 1.

Williamson, S.M. \& Wright, G.A. (2013) Exposure to multiple cholinergic pesticides impairs olfactory learning and memory in honeybees. Journal of Experimental Biology, 216, 1799-1807.

Winfree, R., Williams, N.M., Dushoff, J. \& Kremen, C. (2007) Native bees provide insurance against ongoing honey bee losses. Ecology Letters, 10, 1105-1113.

Zayed, A. \& Packer, L. (2005) Complementary sex determination substantially increases extinction proneness of haplodiploid populations. Proceedings of the National Academy of Sciences of the United States of America, 102, 10742-10746.

Accepted 28 October 2013

First published online 26 December 2013 